\title{
Commentary: Optimal perfusion strategy for stroke risk reduction in type $A$ aortic dissection repair-Still unresolved?
}

Konstantin von Aspern, MD, Christian D. Etz, MD, PhD, and Michael A. Borger, MD, PhD

From the University Department for Cardiac Surgery, Leipzig Heart Center, Leipzig, Germany.

Disclosures: Authors have nothing to disclose with regard to commercial support.

Received for publication July 31, 2019; revisions received Aug 1, 2019; accepted for publication Aug 4, 2019; available ahead of print Oct 1, 2019.

Address for reprints: Michael A. Borger, MD, PhD, University Department for Cardiac Surgery, Leipzig Heart Center, Struempellstrasse 39 04289, Leipzig, Germany (E-mail: michael.borger@ helios-kliniken.de).

J Thorac Cardiovasc Surg 2020;159:2157-8

$0022-5223 / \$ 36.00$

Copyright (c) 2019 by The American Association for Thoracic Surgery

https://doi.org/10.1016/j.jtcvs.2019.08.029

Acute aortic dissection type $\mathrm{A}$ is one of the most devastating acute pathologies in cardiac surgery, being associated with a significant risk of major morbidity and mortality. The primary treatment goal of surgery is to ensure the patient's survival and terminate acute end-organ ischemia, with prevention of future adverse events from the structurally injured downstream aortic wall as an important secondary goal. Even in experienced aortic centers, morbidity and mortality remain significant for this challenging pathology. ${ }^{1-5}$ One of the most disastrous complications remains permanent neurologic impairment as a result of cerebral stroke. ${ }^{1,4}$

Since the early days of successful type A dissection repair by De Bakey and associates in the 1950s, ${ }^{6,7}$ technical adjustments have led to significant improvements in postoperative morbidity and mortality. With the advent of cerebral perfusion and the implementation of novel neuromonitoring methods, many surgeons have also opted for higher intraoperative core temperatures without seeing a significant increase in postoperative neurologic complications. ${ }^{5,8}$

In this issue of the Journal, Ghoreishi and colleagues ${ }^{9}$ shed light on the association of different operative strategies in type A repair with regard to stroke risk. In their studyrepresenting the largest registry-based cohort analysis on this topic to date-Ghoreishi and colleagues ${ }^{9}$ provide valuable benchmark data on operative management of this pathology, add more insight into the long-contested issue of optimal cannulation technique, and describe potential advantages of a controversial cerebral protection strategy: retrograde cerebral perfusion (RCP).

Most of the findings of Ghoreishi and colleagues ${ }^{9}$ are consistent with previous studies on this topic. With a mortality of $17 \%$ and a new-onset postoperative stroke rate of $13 \%$, the results are in line with comparable large registry analyses, such as the German Registry for Acute Aortic

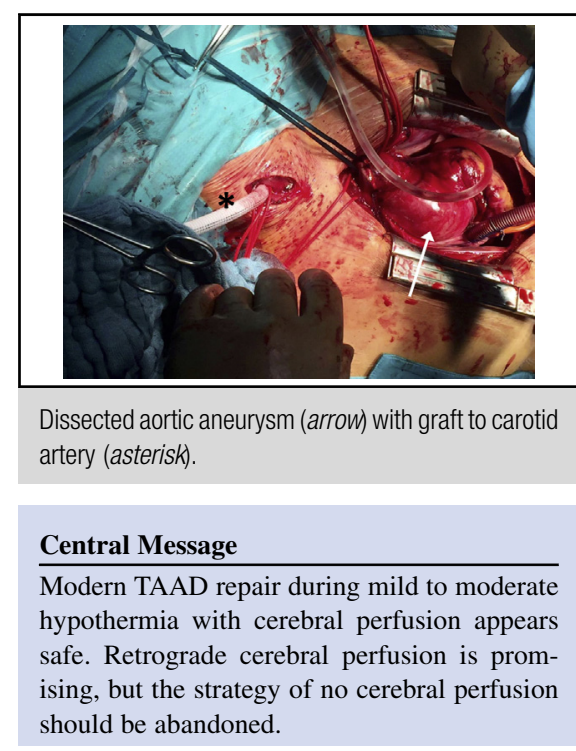

See Article page 2143.

Dissection Type $\mathrm{A}^{2}$ and the International Registry of Acute Aortic Dissection. ${ }^{10}$ An interesting observation in the study of Ghoreishi and colleagues ${ }^{9}$ is that the degree of hypothermia did not seem to significantly affect neurologic outcome, a reassuring finding given the previously mentioned general trend toward higher core temperatures during arch surgery. Interpretation of this finding, however, also requires consideration of the implemented cerebral perfusion strategy, the extent of aortic wall destruction, and the preoperative clinical status of the patient. Generally speaking, procedures performed during moderate or mild hypothermia used some sort of cerebral perfusion strategy, whereas surgery without cerebral perfusion necessitates deep or profound hypothermia. Direct comparison of these strategies would therefore require thorough analyses of the previously mentioned variables and selection criteria as possible confounders.

The most interesting finding of the study of Ghoreishi and colleagues ${ }^{9}$ is the protective influence of RCP on postoperative stroke. Efficacy of RCP has been a controversial topic in aortic arch surgery for many years, with some investigators finding inferior results for RCP relative to antegrade cerebral perfusion (ACP) ${ }^{11}$ In their risk regression model, Ghoreishi and colleagues ${ }^{9}$ compared the effects of different cerebral protection strategies (ACP, RCP, and none) on 
stroke. The reference (comparison) value for this variable was no cerebral perfusion. Given the fact that no cerebral perfusion was associated with the highest incidence of stroke, the advantageous effect of RCP could be shown only in comparison to no cerebral perfusion, a strategy that is being used with decreasing frequency in current clinical practice. ${ }^{3,12}$ A direct comparison between RCP and ACP revealed no significant difference in stroke rate $(11.4 \%$ vs $12.8 \% ; P=.155)$. Contemporary data on large patient cohorts reveal postoperative stroke rates between $6 \%$ and $10 \%$ when using unilateral or bilateral ACP. ${ }^{1,5,12}$ Even for prolonged cerebral perfusion times (ie, longer than 60 minutes), stroke rates of only $8 \%$ have been demonstrated with ACP. ${ }^{13}$

Ghoreishi and colleagues ${ }^{9}$ were able to confirm that no cerebral perfusion yields worse results than any other cerebral perfusion strategy in terms of postoperative stroke, a finding that has been demonstrated many times before. Potential superiority of RCP during type A aortic dissection repair, however, requires further investigation. What we can conclude with a high degree of certainty is that no cerebral perfusion during type A dissection surgery-and indeed, during any aortic arch surgery-is an inferior technique that should be abandoned without further delay.

\section{References}

1. Boening A, Karck M, Conzelmann LO, Easo J, Krüger T, Rylski B, et al. German Registry for Acute Aortic Dissection Type A: structure, results, and future perspectives. Thorac Cardiovasc Surg. 2017;65:77-84.

2. Conzelmann LO, Weigang E, Mehlhorn U, Abugameh A, Hoffmann I, Blettner M, et al. Mortality in patients with acute aortic dissection type A: analysis of pre- and intraoperative risk factors from the German Registry for Acute
Aortic Dissection Type A (GERAADA), Eur J Cardiothorac Surg. 2016;49: e44-52.

3. Lee TC, Kon Z, Cheema FH, Grau-Sepulveda MV, Englum B, Kim S, et al. Contemporary management and outcomes of acute type A aortic dissection: an analysis of the STS adult cardiac surgery database. J Card Surg. 2018;33: 7-18.

4. Pape LA, Awais M, Woznicki EM, Suzuki T, Trimarchi S, Evangelista A, et al. Presentation, diagnosis, and outcomes of acute aortic dissection: 17-year trends from the International Registry of Acute Aortic Dissection. J Am Coll Cardiol. 2015:66:350-8

5. Zierer A, El-Sayed Ahmad A, Papadopoulos N, Detho F, Risteski P, Moritz A, et al. Fifteen years of surgery for acute type A aortic dissection in moderate-to-mild systemic hypothermia†. Eur J Cardiothorac Surg. 2017; 51:97-103

6. Hirst AE Jr, Johns VJ Jr, Kime SW Jr. Dissecting aneurysm of the aorta: a review of 505 cases. Medicine. 1958;37:217-79.

7. De Bakey ME, Cooley DA, Creech OJ. Surgical treatment of dissecting aneurysm. JAMA. 1956;162:1654-7.

8. Etz CD, von Aspern K, da Rocha e Silva J, Girrbach FF, Leontyev S, Luehr M, et al. Impact of perfusion strategy on outcome after repair for acute type A aortic dissection. Ann Thorac Surg. 2014;97:78-85.

9. Ghoreishi M, Sundt TM, Cameron D, Holmes SD, Roselli EE, Pasrija C, et al. Factors associated with acute stroke after type A aortic dissection repair: an analysis of the Society of Thoracic Surgeons National Adult Cardiac Surgery Database. J Thorac Cardiovasc Surg. 2020;159:2143-54.e3.

10. Evangelista A, Isselbacher EM, Bossone E, Gleason TG, Eusanio MD, Sechtem U, et al; IRAD Investigators. Insights from the International Registry of Acute Aortic Dissection: a 20-year experience of collaborative clinical research. Circulation. 2018;137:1846-60.

11. Misfeld M, Leontyev S, Borger MA, Gindensperger O, Lehmann S, Legare JF, et al. What is the best strategy for brain protection in patients undergoing aortic arch surgery? A single center experience of 636 patients. Ann Thorac Surg. 2012; 93:1502-8.

12. Keeling WB, Leshnower BG, Hunting JC, Binongo J, Chen EP. Hypothermia and selective antegrade cerebral perfusion is safe for arch repair in type A dissection. Ann Thorac Surg. 2017;104:767-72.

13. El-Sayed Ahmad A, Papadopoulos N, Risteski P, Hack T, Ay M, Moritz A, et al. Is more than one hour of selective antegrade cerebral perfusion in moderate-to-mild systemic hypothermic circulatory arrest for surgery of acute type A aortic dissection safe? Thorac Cardiovasc Surg. 2018;66: 215-21. 